\title{
Resonance Raman study of the A-band short-time photodissociation dynamics of axial and equatorial conformers of iodocyclopentane
}

\author{
Xuming Zheng, Cheong Wan Lee, and David Lee Phillips ${ }^{\text {a) }}$ \\ Department of Chemistry, University of Hong Kong, Pokfulam Road, Hong Kong
}

(Received 20 May 1999; accepted 29 September 1999)

\begin{abstract}
We have obtained resonance Raman spectra of iodocyclopentane in cyclohexane solution at three excitation wavelengths resonant with the $A$-band absorption. The $A$-band resonance Raman spectral bands can be assigned to fundamentals, overtones, and combination bands of seven axial conformer and eight equatorial conformer Franck-Condon active modes. The resonance Raman and absorption cross sections were simultaneously simulated using wave packet calculations and a simple model. The best fit parameters of the simulations and the normal mode descriptions were used to determine the $A$-band short-time photodissociation dynamics of the axial and equatorial conformers of iodocyclopentane. The axial and equatorial conformers exhibit noticeably different short-time photodissociation dynamics that suggest that the $\mathrm{C}-\mathrm{I}$ bond cleavage process is conformation dependent. The axial conformer short-time photodissociation dynamics have larger changes in the carbon-carbon stretch and three carbon atom bending motions as well as the torsional motion about the $\alpha$ and $\beta$ carbon atom bond. The CCI bending motions for the axial and equatorial conformers of iodocyclopentane as well as previously reported results for the equatorial conformer of iodocyclohexane are significantly smaller than CCI bending motions found for most noncyclic iodoalkanes examined so far. This suggests that the cyclic backbone restricts the initial motion of the $\mathrm{C}-\mathrm{I}$ bond cleavage along the CCI bend in iodocycloalkanes compared to the noncyclic iodoalkanes. (C) 1999 American Institute of Physics. [S0021-9606(99)00948-4]
\end{abstract}

\section{INTRODUCTION}

Iodoalkanes have long been investigated in the $A$-band absorption $(\sim 260 \mathrm{~nm})$ as a model for direct photodissociation reactions. ${ }^{1-79}$ A great deal of experimental and theoretical work has been done to elucidate the photodissociation dynamics, the energy disposal, the branching ratio of the ${ }^{3} Q_{0}$ and ${ }^{1} Q_{1}$ curve crossing and other aspects of the direct photodissociation reactions of iodoalkanes. ${ }^{1-80}$ However, there have not been very many investigations of the effect of geometrical conformation on the dynamics and energy disposal of $A$-band photodissociation of iodoalkanes. A time-of-flight photofragment translational spectroscopy study of the $A$-band iodocyclohexane photodissociation determined the translational energy distributions of the $\mathrm{I}^{*}$ and I fragments and found that the axial conformer receives 6.0 $\pm 0.8 \mathrm{kcal} / \mathrm{mol}$ more translational energy than the equatorial conformer. $^{81}$ This indicates that the cyclohexyl radical produced from the equatorial conformation $A$-band photodissociation receive more internal excitation than the cyclohexyl radicals produced from the axial conformation photodissociation. A resonance Raman examination of the A-band short-time photodissociation dynamics of the equatorial conformer of iodocyclohexane found that the initial $\mathrm{C}-\mathrm{I}$ bond length changes suggest the cyclohexyl radical gains substantial internal excitation ${ }^{82}$ consistent with the time-of-flight photofragment translational spectroscopy study. ${ }^{81}$ Comparison of the short-time photodissociation dynamics results for $A$-band iodocyclohexane with previous results found for sev-

a) Author to whom correspondence should be addressed. eral noncyclic iodoalkanes ${ }^{79}$ suggested that the geometry of the $\mathrm{C}-\mathrm{I}$ bond relative to the plane of the $\alpha-, \beta$-, and $\gamma$-carbon atoms of the cylohexyl group is important in deciding the amount of internal excitation of the cyclohexyl fragment. ${ }^{82}$ The time-of-flight photofragment spectroscopy and resonance Raman spectroscopy experimental results ${ }^{81,82}$ imply that the two different geometrical conformations (axial and equatorial) of iodocyclohexane have significantly different photodissociation dynamics and energy disposal. Single bond rotational conformers have also been investigated for 1-iodopropane $A$-band photodissociation in the gas and solution phases. ${ }^{65,79}$ Resonance Raman experiments showed that the trans and gauche conformers of 1-iodopropane have significantly different multidimensional short-time photodissociation dynamics that can in large part be attributed to the position of the $\mathrm{C}-\mathrm{I}$ bond relative to the plane of the three carbon atoms of the $n$-propyl group in 1-iodopropane. ${ }^{79} \mathrm{Mo}-$ lecular beam experiments suggested that the $n$-propyl radicals formed from $A$-band photodissociation of trans and gauche conformations of 1-iodopropane had similar broad translational energy distributions. ${ }^{6}$ However, the different short-time photodissociation dynamics for the trans and gauche conformations of 1-iodopropane ${ }^{79}$ suggests that the energy disposal is likely distributed among significantly different distributions among the internal degrees of freedom for the $n$-propyl radicals formed from the trans and gauche conformers of 1-iodopropane.

In this paper, we examine the short-time photodissociation dynamics of the axial and equatorial conformers of iodocyclopentane. Most halocyclopentanes display signifi- 
cantly different conformational preferences compared to halocyclohexanes. ${ }^{83-88}$ The equatorial conformation is generally more stable than the axial conformation for halocyclohexanes ${ }^{89-91}$ while the axial conformation is usually more stable than the equatorial conformation for halocyclopentanes like chlorocylopentane. ${ }^{83-88}$ For iodocyclohexane in room temperature solutions (and in the gas phase) the equatorial conformation has most of the population relative to the axial conformation (for acetonitrile solvent the relative populations are $\sim 78 \%$ equatorial and $\sim 22 \%$ axial conformations). ${ }^{82}$ This made it difficult to extract reliable axial resonance Raman band intensities from the $A$-band resonance Raman spectra of iodocyclohexane and prevented a detailed comparison of the equatorial and axial conformation short-time photodissociation dynamics. ${ }^{82}$ For iodocyclopentane, the relative populations of the axial and equatorial conformations are more similar to one another (about 50\% for each conformer $)^{80}$ and this allows us to obtain information about both conformations and a detailed comparison of the $A$-band short-time photodissociation dynamics.

\section{EXPERIMENT}

Samples for the resonance Raman experiments were prepared using iodocyclopentane $(99 \%)$ and spectroscopic grade cyclohexane $(99.9+\%)$ purchased from Aldrich. Sample concentrations ranging from 0.10 to $0.15 \mathrm{M}$ iodocyclopentane in cyclohexane solvent were used in the Raman experiments. The methods and apparatus used for the resonance Raman spectroscopy experiments have been previously described $^{69-79}$ and only a short description will be given here. The harmonics of a nanosecond Nd:YAG laser (Spectra-Physics GCR-150-10) and their hydrogen Raman shifted lines gave the excitation wavelengths for the resonance Raman experiments. The excitation laser beam was loosely focused $(50-100 \mu \mathrm{J}$ and $\sim 0.5 \mathrm{~mm}$ diam) onto a flowing liquid sample using a backscattering geometry. The resonance Raman scattered light was collected using reflective optics and imaged through a depolarizer and entrance slits of a $0.5 \mathrm{~m}$ spectrograph. The 1200 groove/mm grating of the spectrograph dispersed the Raman light onto a liquid nitrogen cooled CCD mounted on the exit of the spectrograph. The Raman signal was acquired for approximately 90-120 s prior to collection by an interfaced PC computer and $10-30$ of these scans were summed to obtain the resonance Raman spectrum.

The Raman shifts of the resonance Raman spectra were calibrated using the known vibrational frequencies of the cyclohexane solvent Raman bands. The resonance Raman spectra were corrected for sample reabsorption as described in Ref. 92. Solvent Raman bands were subtracted from the resonance Raman spectra using an appropriately scaled solvent spectrum. Spectra of an intensity calibrated deuterium lamp were used to correct the resonance Raman spectral intensities for the variation in detection efficiency as a function of wavelength. Portions of the resonance Raman spectra were fitted to a baseline plus a sum of Lorentzian bands to obtain the integrated areas of the Raman bands.

The absolute resonance Raman cross sections of iodocyclopentane were determined relative to the $802 \mathrm{~cm}^{-1}$ cyclo- hexane solvent band. ${ }^{93,94}$ The concentrations of the iodocyclopentane sample solutions were measured before and after each Raman cross section measurement using an ultravioletvisible spectrometer. During the absolute Raman cross section measurements, the absorption spectra changed by less than $5 \%$ due to photodecomposition and/or solvent evaporation. The absolute Raman cross sections were computed using the average concentration obtained from the before and after absorption spectrum for each Raman measurement and the mean of three runs was used to get the final value for each wavelength.

\section{CALCULATIONS}

\section{A. Time-dependent wave packet calculations and normal coordinate computations}

A simple model and wave packet calculations ${ }^{95-99}$ were used to simulate the absorption spectrum and resonance Raman intensities. These calculations and model are not meant to be a complete description of the absorption and resonance Raman spectra, but are used to extract the main features of the short-time photodissociation dynamics for the axial and equatorial conformers of iodocyclopentane. Since the direct $\mathrm{C}-\mathrm{I}$ bond cleavage of iodoalkanes is typically $<100 \mathrm{fs}$ and the axial to equatorial interconversion of iodocyclopentane takes a much longer time, the axial and equatorial conformers likely do not interconvert during the $A$-band photodissociation. Thus, the iodocyclopentane molecules in the axial conformer at the time of photoexcitation will lead to an axial absorption and resonance Raman spectrum while the molecules in the equatorial conformer at the time of photoexcitation will lead to an equatorial absorption and resonance Raman spectrum. The absorption spectra and resonance Raman cross sections were computed for each conformer and then added together (weighted by their relative populations at $298 \mathrm{~K}$ ) to obtain the total absorption spectrum and resonance Raman cross sections that were fit to the experimental absorption spectrum and resonance Raman cross sections.

A time-dependent approach ${ }^{95-99}$ was used to compute the absorption spectrum of each conformer using the following equation:

$$
\begin{aligned}
\sigma_{A}\left(E_{L}\right)= & \left(4 \pi e^{2} E_{L} M^{2} / 3 n \hbar^{2} c\right) \Sigma_{i} P_{i} \\
& \times \operatorname{Re}\left[\int_{0}^{\infty}\langle i \mid i(t)\rangle \exp \left[i\left(E_{L}+\epsilon_{i}\right) t / \hbar\right]\right. \\
& \times \exp [-g(t)] d t] .
\end{aligned}
$$

The resonance Raman cross sections of each conformer were calculated from

$$
\sigma_{R}\left(E_{L}, \omega_{s}\right)=\Sigma_{i} \Sigma_{f} P_{i} \sigma_{R, i \rightarrow f}\left(E_{L}\right) \delta\left(E_{L}+\epsilon_{i}-E_{s}-\epsilon_{f}\right)
$$

with

$$
\begin{aligned}
\sigma_{R, i \rightarrow f}\left(E_{L}\right)= & \left(8 \pi e^{4} E_{S}^{3} E_{L} M^{4} / 9 \hbar^{6} c^{4}\right) \mid \\
& \int_{0}^{\infty}\langle f \mid i(t)\rangle \exp \left[i\left(E_{L}+\epsilon_{i}\right) t / \hbar\right] \\
& \times\left.\exp [-g(t)] d t\right|^{2},
\end{aligned}
$$


where $E_{L}$ is the incident photon energy, $E_{s}$ is the scattered photon energy, $n$ is the solvent index of refraction, $M$ is the transition length evaluated at the equilibrium geometry, and $\delta\left(E_{1}+\epsilon_{i}-E_{s}-\epsilon_{f}\right)$ is a delta function to add up cross sections with the same frequency. $P_{i}$ is the initial Boltzmann population of the ground-state energy level $|i\rangle$ which has energy $\epsilon_{i}, f$ is the final state for the resonance Raman process, and $\epsilon_{f}$ is the energy of the ground state energy level $\left.|f\rangle,|i(t)\rangle=e^{-i H t / \hbar \mid} i\right\rangle$ which is $|i(t)\rangle$ developed on the excited electronic state surface for a time $t$ by the excited state vibrational Hamiltonian, $H$. The $\exp [-g(t)]$ term in Eqs. (1) and (2) is a damping function dependent on the electronic dephasing in the molecular system and for $A$-band iodocyclopentane this is expected to be mainly direct photodissociation population decay with some solvent dephasing.

The ground and excited state potential energy surfaces were approximated using harmonic oscillators displaced by $\Delta$ in dimensionless normal coordinates. The resonance Raman intensities of the first several overtones as well as combination bands and the absorption spectrum are determined mainly by the slope of the excited state surface in the Franck-Condon region in the absence of any vibrational recurrences. The featureless gas and solution phase $A$-band absorption spectra for iodocyclopentane suggests the total electronic dephasing is mostly from direct photodissociation prior to the first vibrational recurrence. A direct photodissociation reaction was approximated by cutting off the wave packet development after 40 fs in order to avoid any significant recurrences of the wave packet to the Franck-Condon region. For the resonance Raman bands observed in our experimental spectra, the $\langle f \mid i(t)\rangle$ overlaps decay and obtain an insignificant value after $30 \mathrm{fs}$. The $[-g(t)]$ term in Eqs. (1) and (2) was replaced by $\exp [-t / \tau]$ to simulate the effects of solvent dephasing. The bound harmonic oscillator model only gives a convenient method to simulate the FranckCondon region part of the excited state surface (that determines the resonance Raman intensities and absorption spectrum) and does not indicate that the excited state is bound. Our simulations only used homogeneous broadening of the lines since this was adequate to simulate the resonance Raman partial excitation profile and absorption cross sections. Inhomogeneous broadening may affect the relative intensities of different bands as well as the resonance Raman cross sections. However, we would expect that any inhomogeneous broadening effects on the $A$-band iodocyclopentane spectra are relatively small since many previous resonance Raman intensity analysis investigations of $A$-band iodoalkanes found little evidence or need to include substantial inhomogeneous broadening to simultaneously model the resonance Raman partial excitation profiles, absolute Raman cross sections, and absorption band. ${ }^{29,31-33,67,72-79,82}$ Possible moderate perturbations of the relative intensities may become discernible when resonance Raman excitation profiles with many data points over the $A$-band absorption become available.

The normal coordinate motions were translated into internal coordinate motions in order to easily picture the $A$-band short-time photodissociation dynamics of the axial and equatorial conformations of iodocyclopentane. The cen- ter of a wave packet at time $t$ after photoexcitation and undergoing separable harmonic dynamics may be specified by

$$
q_{\alpha}(t)=\Delta_{\alpha}\left(1-\cos \omega_{\alpha} t\right),
$$

where the time, $t$, is in units of fs, and the vibrational frequency, $\omega_{\alpha}$, is in units of $\mathrm{fs}^{-1}$. For each mode $\alpha$ at the ground electronic state equilibrium geometry we fix $q_{\alpha}=0$. The internal coordinate displacements at different times $t$ are then found from $q_{\alpha}(t)$ by

$$
s_{i}(t)=(h / 2 \pi c)^{1 / 2} \Sigma_{\alpha} A_{\alpha i} \bar{\omega}_{\alpha}^{-1 / 2} q_{\alpha}(t),
$$

where $s_{i}$ are the displacements of the internal coordinates (bond stretches, bends, torsions, and wags as defined by Wilson, Decius, and Cross ${ }^{100}$ from their ground electronic state equilibrium values $\bar{\omega}_{\alpha}$ is the vibrational frequency (in $\mathrm{cm}^{-1}$ ) and $A_{\alpha i}$ is the normal mode coefficient $\left(\partial s_{i} / \partial Q_{\alpha}\right)$, where $Q_{\alpha}$ is the ordinary dimensioned normal coordinate. The normal-mode vectors for the axial and equatorial conformations of iodocyclopentane were found using an adapted version of the Snyder and Schactschneider FG program. ${ }^{101}$ Previously reported $a b$ initio optimized geometries and force field ${ }^{80}$ were adjusted moderately to better fit the vibrational frequencies. The adjusted force field resulted in a root-meansquare (rms) frequency error of $6.3 \mathrm{~cm}^{-1}$ for the axial conformation and $7.2 \mathrm{~cm}^{-1}$ for the equatorial conformation of iodocyclopentane. The complete force field, Cartesian coordinates, calculated vibrational frequencies and normal-mode coefficients are available as supporting information (EPAPS). ${ }^{102}$ Table I shows the ground state normal mode descriptions of the $A$-band Franck-Condon active vibrational modes for the axial and equatorial conformers of iodocyclopentane (only diagonal contributions to the potential energy distributions are shown).

\section{B. $A b$ initio calculation of the excited state gradient at the ground state geometry}

The relative normal mode displacement $\Delta_{i}$ using the short-time approximation can be given by

$$
\Delta_{i}=k \omega_{i}^{-3 / 2}\left(\partial V / \partial Q_{i}\right)_{0},
$$

where $\left(\partial V / \partial Q_{i}\right)_{0}$ is the derivative of the excited electronic state potential energy surface with respect to the $i$ th normal mode at the ground state geometry. We have performed $a b$ initio calculations to estimate the sign and magnitude of the normal mode displacements associated with the excited states of the equatorial and axial conformations of iodocyclopentane. The G98w version of the Gaussian suite of programs was employed for all of the $a b$ initio calculations reported here. ${ }^{103}$ We performed CIS (singles CI) $/ 3-21 G^{*} / /$ Becke3P86/3-21G* and DT(RPA) (timedependent density functional theory at random phase approximation $)^{104}$ /3-21G*//Becke3P86/3-21G* computations. First, we found the ground state optimized geometry for the axial and equatorial conformations of iodocyclopentane using Becke3P86/3-21G* density functional theory calculations. The normal mode vibrational frequency computations were then done at the ground state optimized geometry for each conformation. The gradient of the potential energy surface of the excited electronic state were obtained using 
TABLE I. Franck-Condon active ground-state normal mode descriptions for axial and equatorial conformers of iodocyclopentane.

\begin{tabular}{|c|c|c|c|}
\hline Vibrational mode & $\begin{array}{c}\text { Expt } \\
\text { Freq. }\left(\mathrm{cm}^{-1}\right)\end{array}$ & $\begin{array}{c}\text { Calc } \\
\text { Freq. }\left(\mathrm{cm}^{-1}\right)\end{array}$ & Potential energy contribution ${ }^{a}$ \\
\hline \multicolumn{4}{|l|}{ Axial conformer } \\
\hline $\mathrm{v}_{11}, \gamma-\mathrm{CH}_{2}$ twist & 1190 & 1189 & HcC $36 \%$, HcX $23 \%$, XX $15 \%$, HXc $12 \%$ \\
\hline $\mathrm{v}_{12}, \alpha-\mathrm{CH}$ bend & 1094 & 1105 & $\mathrm{ICH} 43 \%, \mathrm{Cc} 21 \%, \mathrm{HCc} 18 \%, \mathrm{HcX} 13 \%$ \\
\hline $\mathrm{v}_{13}$, ring deformation & 1034 & 1024 & $\mathrm{ICH} 29 \%, \mathrm{Cc} 12 \%, \mathrm{HCc} 18 \%$ \\
\hline $\mathrm{v}_{15}, \beta-\mathrm{CH}_{2}$ rock & 903 & 900 & $\mathrm{HcX} 28 \%, \mathrm{HcC} 22 \%$, Cc $18 \%, \mathrm{HXX} 10 \%$ \\
\hline $\mathrm{v}_{18}, \mathrm{C}-\mathrm{I}$ stretch & 672 & 669 & $\begin{array}{l}\text { CI } 36 \%, \text { ICc } 17 \%, \text { HCc } 17 \%, \operatorname{HcX} 12 \% \text {, } \\
\text { XcC } 13 \%\end{array}$ \\
\hline $\mathrm{v}_{19}, \mathrm{cCc}$ bend & 481 & 481 & $\begin{array}{l}\text { XcC } 37 \%, \operatorname{cCc} 26 \%, \operatorname{HcC} 22 \%, \operatorname{HcX} 17 \%, \\
\text { Cc } 17 \%, \mathrm{Cl} 15 \%, \operatorname{cXX} 13 \%\end{array}$ \\
\hline $\mathrm{v}_{20}, \mathrm{C}-\mathrm{I}$ stretch & 286 & 282 & CI $45 \%$, ICc $20 \%$ \\
\hline \multicolumn{4}{|l|}{ Equatorial conformer } \\
\hline $\mathrm{v}_{8}, \beta-\mathrm{CH}_{2}$ wag & 1308 & 1309 & HcC $24 \%$, Cc $20 \%, \operatorname{HcX} 17 \%$ \\
\hline $\mathrm{v}_{11}, \gamma-\mathrm{CH}_{2}$ twist & 1190 & 1199 & $\mathrm{HcC} 41 \%, \operatorname{HcX} 28 \%, \operatorname{HXX} 11 \%$ \\
\hline $\mathrm{v}_{12}, \alpha-\mathrm{CH}$ bend & 1110 & 1108 & ICH $53 \%$, Hcc $25 \%$, HcC $12 \%$ \\
\hline $\mathrm{v}_{13}$, ring deformation & 1026 & 1019 & Cc $26 \%$, Hcc $16 \%$, ICH $15 \%$, HcX $14 \%$ \\
\hline $\mathrm{v}_{16}, \gamma-\mathrm{CH}_{2}$ rock & 876 & 879 & HXX 44\%, Hxc 33\%, XX 29\% \\
\hline $\mathrm{v}_{18}, \mathrm{C}-\mathrm{I}$ stretch & 693 & 692 & CI $47 \%$, ICc $18 \%$, XcC $22 \%, \mathrm{HcX} 11 \%$. \\
\hline $\mathrm{V}_{19}, \mathrm{cCc}$ bend & 430 & 430 & $\begin{array}{l}\text { cCc } 25 \%, \text { Hcc } 16 \%, \text { HcC } 14 \%, \text { Cc } 10 \% \text {, } \\
\text { cXX } 11 \%\end{array}$ \\
\hline $\mathrm{v}_{20}, \mathrm{C}-\mathrm{I}$ stretch & 249 & 245 & CI $44 \%$, ICc $21 \%$, XcC $16 \%$ \\
\hline
\end{tabular}

${ }^{\mathrm{a}}$ Diagonal force constants contributing $10 \%$ or more to the total potential energy of the normal mode are listed.

either the CIS/3-21G* or the DT(RPA)/3-21G* calculations. $\left(\partial V / \partial Q_{i}\right)_{0}$ can be computed from projection of the potential energy surface of the excited electronic state at the ground state geometry onto the $i$ th ground state vibrational normal mode. In Eq. (5), the sign of the normal mode displacement is determined by $\left(\partial V / \partial Q_{i}\right)_{0}$. We used the signs of the normal mode displacements found from our ab initio calculation determine the signs of the normal mode displacements derived from our resonance Raman intensity analysis of our experimental spectra. The ground state optimized geometry and vibrational frequencies for the Becke3P86/3-21G* calculations and the gradients found from the DT(RPA)/3-21G* calculations are available as supporting information. ${ }^{102}$

\section{RESULTS AND DISCUSSION}

Figure 1 shows the geometry of the axial and equatorial conformations of iodocyclopentane (note: $\mathrm{C}=$ the alpha carbon atom, $\mathrm{c}=$ the beta carbon atom, and $\mathrm{X}=$ the gamma carbon atom and the hydrogen atoms are labeled with subscripts a-f) as well as the absorption spectrum of spectrum of iodocyclopentane in cyclohexane solution. The excitation wavelengths for the resonance Raman experiments are shown above the absorption spectrum in Fig. 1. The absorption spectrum is broad, featureless and very similar to $A$-band absorption spectra in other iodoalkanes. ${ }^{27-68}$ The $n$ $\rightarrow \sigma^{*}{ }^{3} Q_{0}$ transition likely accounts for most of the oscillator strength of the iodocyclopentane $A$-band absorption similar to the case for most other iodoalkanes. The bandshape and bandwidth of the iodocyclopentane $A$-band absorption is also very close to those of iodoalkanes that do not have geometrical conformers and this suggests that the axial and equatorial conformations of iodocyclopentane have absorption transitions at very similar energies and likely have bandshapes similar to other iodoalkanes.

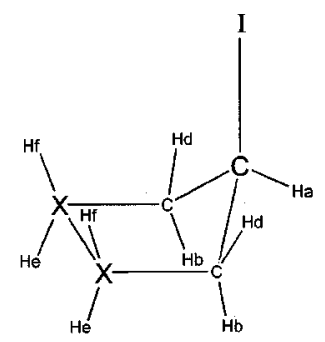

Axial-Iodocyclopentane

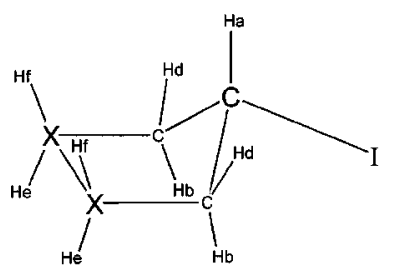

Equatorial-Iodocyclopentane

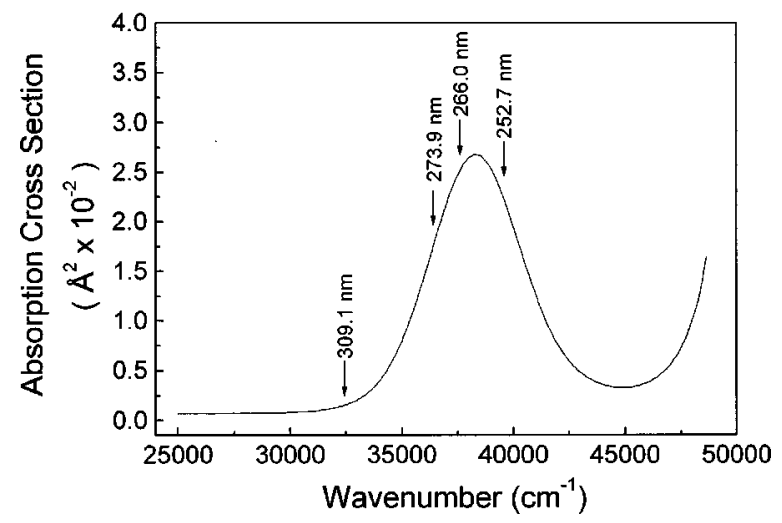

FIG. 1. (Top) Simple diagrams of the axial and equatorial conformers of iodocyclopentane which can be used to help better visualize the short-time dynamics given in Table IV. (Bottom) Absorption spectrum of iodocyclopentane in cyclohexane solution at room temperature. The excitation wavelengths for the resonance Raman experiments are shown above the spectrum. 


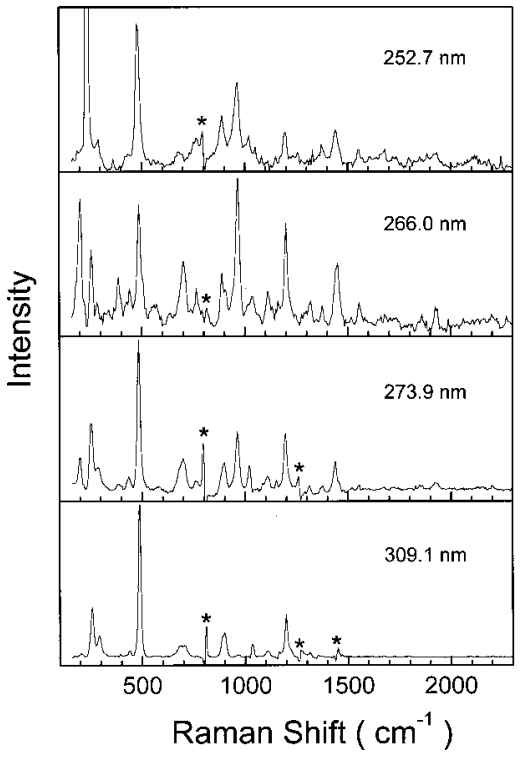

FIG. 2. Overview of the A-band resonance Raman spectra of iodocyclopentane in cyclohexane solution. The spectra have been intensity corrected and solvent subtracted (asterisks mark regions where solvent subtraction artifacts are present).

Figure 2 presents an overview of the $A$-band resonance Raman spectra of iodocyclopentane and Fig. 3 shows an expanded view of the $252.7 \mathrm{~nm}$ resonance Raman spectrum. The spectra shown in Figs. 2 and 3 have been corrected for sample reabsorption as well as the wavelength dependence sensitivity of the detection system. Solvent Raman bands were removed from the spectra by subtracting an appropriately scaled solvent spectrum and regions with solvent subtraction artifacts have been labeled with an asterisk. The larger Raman bands in the spectrum of Fig. 3 are labeled with tentative band assignments based on previously reported Raman spectra. ${ }^{80}$ The intensity of a single Raman feature may have contributions from several Raman bands with very similar Raman shifts due to the limited resolution of the solution phase spectra. Therefore, the Raman band labels in Fig. 3 only show the biggest Raman band contribu-

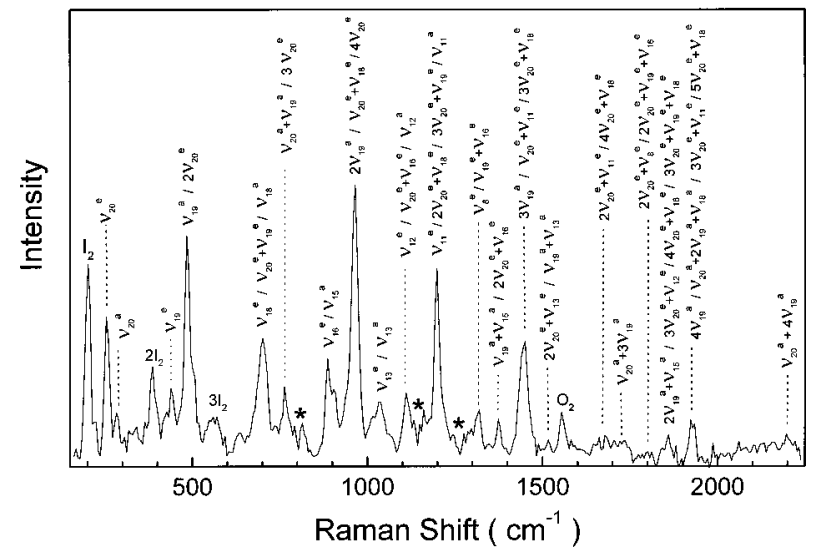

FIG. 3. Enlarged view of the $252.7 \mathrm{~nm}$ resonance Raman spectrum of iodocyclopentane in cyclohexane solution. The spectrum has been intensity corrected and solvent subtracted. Asterisks label parts of the spectrum where solvent subtraction artifacts are present. The tentative assignments of the larger contributions to the larger Raman bands are also shown. tions to each Raman feature. Most of the resonance Raman intensity can be assigned to fundamentals, overtones and combination bands of several Franck-Condon active modes for the axial and equatorial conformations of iodocyclopentane. The axial conformation has about seven FranckCondon active modes: the $\mathrm{C}-\mathrm{I}$ stretch $\mathrm{V}_{20}\left(286 \mathrm{~cm}^{-1}\right)$ and $\mathrm{V}_{18}\left(672 \mathrm{~cm}^{-1}\right)$, the cCc bend $\mathrm{V}_{19}\left(481 \mathrm{~cm}^{-1}\right)$, the $\beta-\mathrm{CH}_{2}$ rock $\mathrm{v}_{15}\left(903 \mathrm{~cm}^{-1}\right)$, the ring deformation $\mathrm{v}_{13}\left(1034 \mathrm{~cm}^{-1}\right)$, the $\alpha-\mathrm{CH}$ bend $\mathrm{v}_{12}\left(1094 \mathrm{~cm}^{-1}\right)$, and the $\gamma-\mathrm{CH}_{2}$ twist $\mathrm{v}_{11}$ $\left(1190 \mathrm{~cm}^{-1}\right)$. The equatorial conformation has about eight Franck-Condon active modes; the $\mathrm{C}-\mathrm{I}$ stretch $\mathrm{V}_{20}$ (249 $\left.\mathrm{cm}^{-1}\right)$ and $\mathrm{v}_{18}\left(693 \mathrm{~cm}^{-1}\right)$, the $\mathrm{cCc}$ bend $\mathrm{v}_{19}\left(430 \mathrm{~cm}^{-1}\right)$, the $\gamma-\mathrm{CH}_{2}$ rock $\mathrm{v}_{16}\left(876 \mathrm{~cm}^{-1}\right)$, the ring deformation $\mathrm{v}_{13}(1026$ $\left.\mathrm{cm}^{-1}\right)$, the $\alpha$-CH bend $\mathrm{V}_{12}\left(1110 \mathrm{~cm}^{-1}\right)$, the $\gamma-\mathrm{CH}_{2}$ twist $\mathrm{v}_{11}$ $\left(1190 \mathrm{~cm}^{-1}\right)$, and the $\beta-\mathrm{CH}_{2}$ wag $\mathrm{v}_{8}\left(1308 \mathrm{~cm}^{-1}\right)$. Some of the axial and equatorial Raman bands are well separated from one another (such as equatorial $v_{20}$ and axial $v_{20}$ ) while others are not well separated from one another in the resonance Raman spectra and appear as the sum of axial and equatorial Raman bands. Most of the resonance Raman intensity appears in the fundamentals, overtones and combination bands of the $\mathrm{C}-\mathrm{I}$ stretch and $\mathrm{cCc}$ bend vibrational modes for both conformations $\left(\mathrm{v}_{20}, \mathrm{v}_{19}\right.$, and $\mathrm{V}_{18}$ modes). This intensity pattern is similar to that observed in other iodoalkane $A$-band resonance Raman spectra. $^{27-36,65-68,76,78,79}$ The multidimensional character of the excited state potential energy surface and/or mixing of the internal coordinates in the ground-state normal mode descriptions complicates the extraction of the short-time photodissociation dynamics from the resonance Raman intensities. To obtain the relative contributions of these two effects and extract the short-time photodissociation dynamics associated with the axial and equatorial conformers of iodocyclopentane we have done a semiquantitative resonance Raman intensity analysis that makes use of the normal-mode descriptions of the Franck-Condon active vibrational modes.

The parameters in Table II and the simple model presented in the Calculations section were used to simulate the absorption and resonance Raman cross sections. Since A-band iodoalkane fundamental resonance Raman bands are prone to interference from preresonance-resonance effects $^{29,33,67,73,76}$ from higher energy excited states, we have given much greater weight to fitting the larger overtone and combination band features. The computed axial and equatorial conformer absorption and resonance Raman cross sections were appropriately weighted $(\sim 50 \%$ axial and $\sim 50 \%$ equatorial as determined by the relative intensities of the 249 $\mathrm{cm}^{-1}$ and $430 \mathrm{~cm}^{-1}$ equatorial bands and the $286 \mathrm{~cm}^{-1}$ and $481 \mathrm{~cm}^{-1}$ axial bands in a FT-Raman spectrum) and summed to give the total absorption and resonance Raman cross sections that were then compared to the experimental values. Figure 4 presents the calculated axial (dotted line) and equatorial (dashed-dotted line) absorption spectra and a comparison of their appropriately weighted sum (dashed line) with the experimental absorption spectrum (solid line). Making allowances that the dominant ${ }^{3} Q_{0}$ transition probably contains about $70 \%-90 \%$ of the $A$-band oscillator strength (as is the case for other iodoalkanes), there is reasonable agreement between the calculated and experimental absorption 
TABLE II. Parameters for simulations of resonance Raman intensities and absorption spectra for axial and equatorial conformers of iodocyclopentane (A) and (B). Comparison of experimental and calculated absolute Raman cross sections for the $4 \mathrm{v}_{20}^{e} / \mathrm{v}_{20}^{e}+\mathrm{v}_{18}^{e} / 2 \mathrm{v}_{19}^{a}$ Raman feature.

\begin{tabular}{lccc}
\hline \hline (A) Axial conformer & $\begin{array}{c}\text { Ground state vibrational } \\
\text { Vibrational mode }\end{array}$ & $\begin{array}{c}\text { Excited state vibrational } \\
\text { frequency }\left(\mathrm{cm}^{-1)}\right.\end{array}$ & $|\Delta|$ \\
\hline $\mathrm{V}_{11}, \gamma$ - $\mathrm{CH}_{2}$ twist & 1190 & 1190 & $0.23 \pm 0.02$ \\
$\mathrm{~V}_{12}, \alpha$-CH bend & 1094 & 1110 & $0.30 \pm 0.03$ \\
$\mathrm{~V}_{13}$, ring deformation & 1034 & 1034 & $0.50 \pm 0.05$ \\
$\mathrm{~V}_{15}, \beta-\mathrm{CH}_{2}$ rock & 903 & 903 & $0.57 \pm 0.05$ \\
$\mathrm{~V}_{18}, \mathrm{C}-\mathrm{I}$ stretch & 672 & 672 & $0.91 \pm 0.05$ \\
$\mathrm{~V}_{19}$, cCc bend & 481 & 481 & $3.75 \pm 0.18$ \\
$\mathrm{~V}_{20}, \mathrm{C}-\mathrm{I}$ stretch & 286 & 286 & \\
Transition length, $M=0.206 \AA$ & $E_{0}=33590 \mathrm{~cm}^{-1}$ & $\Gamma=350 \mathrm{~cm}^{-1}$ & \\
$n=1.426$ & & &
\end{tabular}

(B) Equatorial conformer

\begin{tabular}{lccc}
\multicolumn{1}{c}{ Vibrational mode } & $\begin{array}{c}\text { Ground state vibrational } \\
\text { frequency }\left(\mathrm{cm}^{-1}\right)\end{array}$ & $\begin{array}{c}\text { Excited state vibrational } \\
\text { frequency }\left(\mathrm{cm}^{-1}\right)\end{array}$ & $|\Delta|$ \\
\hline $\mathrm{V}_{8}, \beta-\mathrm{CH}_{2}$ wag & 1308 & 1308 & $0.27 \pm 0.03$ \\
$\mathrm{~V}_{11}, \gamma-\mathrm{CH}_{2}$ twist & 1190 & 1190 & $0.38 \pm 0.03$ \\
$\mathrm{~V}_{12}, \alpha-\mathrm{CH}$ bend & 1110 & 1110 & $0.30 \pm 0.03$ \\
$\mathrm{~V}_{13}$, ring deformation & 1026 & 1026 & $0.35 \pm 0.04$ \\
$\mathrm{~V}_{16}, \gamma-\mathrm{CH}_{2}$ rock & 876 & 876 & $0.57 \pm 0.06$ \\
$\mathrm{~V}_{18}, \mathrm{C}-\mathrm{I}$ stretch & 693 & 693 & $0.78 \pm 0.08$ \\
$\mathrm{~V}_{19}$, cCc bend & 430 & 430 & $1.20 \pm 0.12$ \\
$\mathrm{~V}_{20}, \mathrm{C}-\mathrm{I}$ stretch & 249 & 249 & $5.25 \pm 0.25$ \\
Transition length, $M=0.206 \AA$ & $E_{0}=33950 \mathrm{~cm}^{-1}$ & $\Gamma=390 \mathrm{~cm}^{-1}$ &
\end{tabular}

(C) Comparison of experimental and calculated absolute Raman cross sections for the $4 \mathrm{v}_{20}^{e} / \mathrm{v}_{20}^{e}+\mathrm{v}_{18}^{e} / 2 \mathbf{v}_{19}^{a}$

\begin{tabular}{cccc} 
& \multirow{2}{*}{$\begin{array}{c}\text { Excitation } \\
\text { wavelength }\end{array}$} & \multicolumn{2}{c}{ Absolute Raman cross section in $\AA^{2} /$ molecule } \\
\cline { 3 - 4 } & $252.7 \mathrm{~nm}$ & $1.03 \times 10^{-10}$ & Calculated \\
\hline $4 \mathrm{~V}_{20}^{e} / \mathrm{v}_{20}^{e}+\mathrm{V}_{18}^{e} 2 \mathrm{v}_{19}^{a}$ & $266.0 \mathrm{~nm}$ & $1.20 \times 10^{-10}$ & $0.91 \times 10^{-10}$ \\
& $273.9 \mathrm{~nm}$ & $0.83 \times 10^{-10}$ & $0.75 \times 10^{-10}$ \\
&
\end{tabular}

spectra. Figure 5 displays a comparison of the calculated and experimental resonance Raman cross sections for $A$-band iodocyclopentane. There is reasonable agreement between most of the calculated and experimental Raman features but

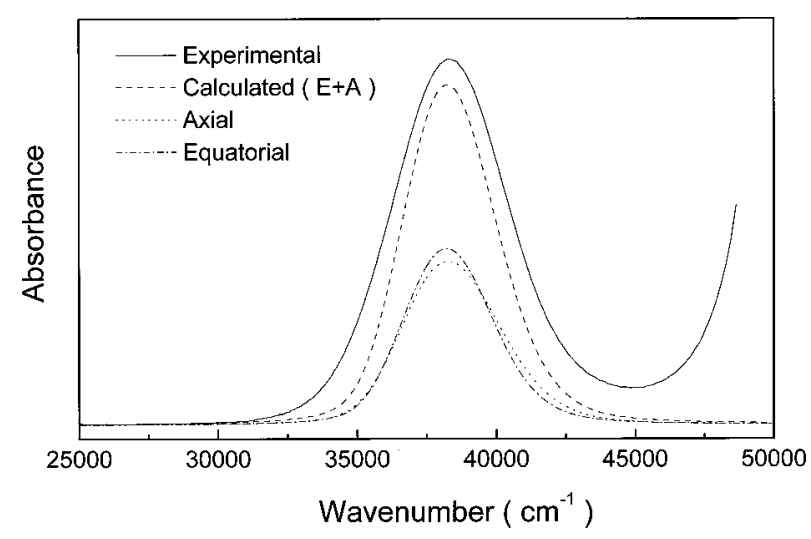

FIG. 4. Comparison of the experimental absorption spectrum (solid line) with the sum (dashed line) of the computed axial (dotted line) and equatorial (dashed-dotted line) absorption spectra. The computed absorption spectra used the parameters of Table II in Eq. (1) and the model described in the Calculations. several bands with contributions from fundamental peaks exhibit poor agreement presumably due to preresonantresonant interference which has been observed for fundamental bands in other iodoalkane $A$-band resonance Raman spectra. ${ }^{29,33,67,73,76}$ Table II also shows a comparison of the experimental and calculated absolute Raman cross sections for the $4 \mathrm{v}_{20}^{e} / \mathrm{v}_{20}^{e}+\mathrm{v}_{18}^{e} / 2 \mathrm{v}_{19}^{a}$ Raman feature (the largest feature with only combination band and overtone contributions) and this displays good agreement between the calculated and experimental values. If any of the parameters of Table II are changed beyond their estimated uncertainties (about $\pm 5 \%-$ $10 \%$; see Table II) the calculated fit to the experimental absorption band and/or resonance Raman cross sections is noticeably poorer. Our overall agreement between the experiment and calculated absorption and resonance Raman cross sections seems reasonable bearing in mind the simple model and approximations used in the calculations. The calculations presented here are intended to provide a reasonable method to obtain the major differences and/or similarities of the axial and equatorial conformers excited state photodissociation dynamics in the Franck-Condon region in a semiquantitative manner (the calculations are not meant to be a 


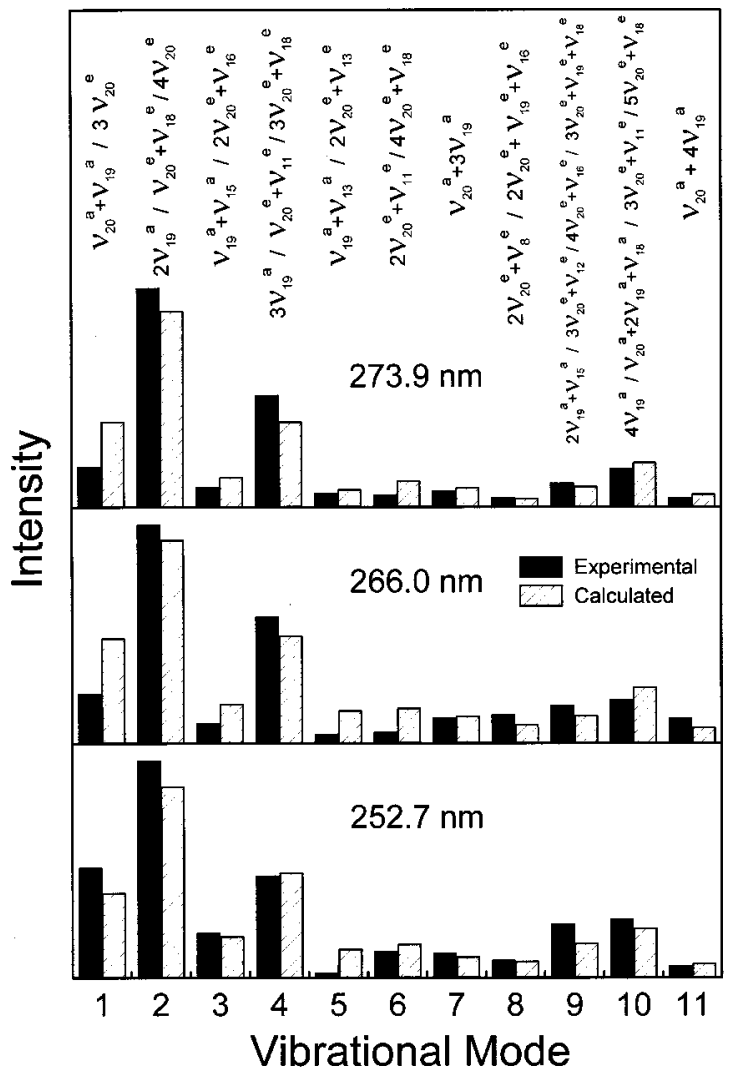

FIG. 5. Comparison of experimental (solid bars) and computed (dashed bars) resonance Raman cross sections. The computed resonance Raman cross sections used the parameters given in Table II in Eq. (2) and the model described in the Calculations.

comprehensive description of the iodocyclopentane $A$-band absorption spectrum and resonance Raman cross sections). The excited state dynamics in the Franck-Condon region associated with the $A$-band photodissociation of the axial and equatorial conformers of iodocyclopentane can be obtained from the best fit normal-mode displacement parameters in Table II.

The normal mode descriptions of the Franck-Condon active vibrational modes were used in conjunction with Eqs. (3) and (4) to elucidate the A-band short-time photodissociation dynamics of the axial and equatorial conformers of iodocyclopentane in terms of internal coordinate motions. We have picked $10 \mathrm{fs}$ as the time to examine the short-time photodissociation dynamics since the $\langle f \mid 0(t)\rangle$ overlaps that help decide the computed resonance Raman intensities usually achieve their maxima about 5-10 fs after photoexcitation. Since the signs of the normal mode displacements are not known, there will be $2^{n}$ ( $n=$ number of Franck-Condon active vibrations) possible sign combinations of the normal coordinate displacements of the Franck-Condon active modes that are equally consistent with the results of the resonance Raman intensity analysis. Because the $\mathrm{C}-\mathrm{I}$ bond is undergoes a direct photodissociation reaction mechanism, we would expect that the $\mathrm{C}-\mathrm{I}$ bond becomes longer upon photodissociation. We have used ab initio calculations to help choose the appropriate sign of the normal mode displacements. ${ }^{105-110}$ Table III compares the results of CIS/3-21G*//Becke3P86/3-21G*, and DT(RPA)/3-21G*// Becke3P86/3-21G* computations for the normal mode displacements with the absolute value of those determined from resonance Raman intensity analysis of the experimental spectra. There is generally reasonable agreement between the calculated and experimental values for the lower frequency modes (below $1000 \mathrm{~cm}^{-1}$ ) associated mainly with the carbon ring and iodine atom as well as the axial $\mathrm{V}_{11}$ mode at 1190 $\mathrm{cm}^{-1}$ and the equatorial $\mathrm{V}_{8}$ mode at $1308 \mathrm{~cm}^{-1}$. These modes account for most of the resonance Raman intensity and associated short-time dynamics. The agreement for the

TABLE III. Comparison of normal mode displacement parameters derived from a resonance Raman intensity analysis of the experimental spectra (experiment) and from CIS/3-21G* (CIS) or the DT(RPA)/3-21G* (RPA) calculations.

\begin{tabular}{|c|c|c|c|c|}
\hline Vibrational mode & $\begin{array}{c}\text { Vibrational } \\
\text { frequency }\left(\mathrm{cm}^{-1}\right)^{\mathrm{a}}\end{array}$ & $\begin{array}{l}\text { Experiment } \\
\qquad|\Delta|\end{array}$ & $\begin{array}{c}\text { Calculated } \Delta \\
\text { CIS }^{\mathrm{b}}\end{array}$ & $\mathrm{RPA}^{\mathrm{b}}$ \\
\hline \multicolumn{5}{|l|}{ (A) Axial conformer } \\
\hline $\mathrm{v}_{11}, \gamma-\mathrm{CH}_{2}$ twist & 1190 & $0.23 \pm 0.02$ & +0.15 & +0.18 \\
\hline $\mathrm{v}_{12}, \alpha-\mathrm{CH}$ bend & 1094 & $0.30 \pm 0.03$ & -0.04 & -0.09 \\
\hline $\mathrm{v}_{13}$, ring deformation & 1034 & $0.50 \pm 0.05$ & -0.04 & -0.02 \\
\hline $\mathrm{v}_{15}, \beta-\mathrm{CH}_{2}$ rock & 903 & $0.57 \pm 0.05$ & -0.34 & -0.31 \\
\hline $\mathrm{v}_{18}, \mathrm{C}-\mathrm{I}$ stretch & 672 & $0.91 \pm 0.05$ & -0.68 & -0.71 \\
\hline $\mathrm{v}_{19}, \mathrm{cCc}$ bend & 481 & $3.75 \pm 0.18$ & -3.75 & -3.75 \\
\hline $\mathrm{V}_{20}, \mathrm{C}-\mathrm{I}$ stretch & 286 & $2.40 \pm 0.10$ & -2.51 & -2.39 \\
\hline \multicolumn{5}{|l|}{ (B) Equatorial conformer } \\
\hline $\mathrm{v}_{8}, \beta-\mathrm{CH}_{2}$ wag & 1308 & $0.27 \pm 0.03$ & +0.17 & +0.19 \\
\hline $\mathrm{v}_{11}, \gamma-\mathrm{CH}_{2}$ twist & 1190 & $0.38 \pm 0.03$ & +0.03 & +0.01 \\
\hline $\mathrm{v}_{12}, \alpha$-CH bend & 1110 & $0.30 \pm 0.03$ & +0.02 & +0.07 \\
\hline $\mathrm{v}_{13}$, ring deformation & 1026 & $0.35 \pm 0.04$ & -0.05 & -0.03 \\
\hline $\mathrm{v}_{16}, \gamma-\mathrm{CH}_{2}$ rock & 876 & $0.57 \pm 0.06$ & -0.17 & -0.18 \\
\hline $\mathrm{v}_{18}, \mathrm{C}-\mathrm{I}$ stretch & 693 & $0.78 \pm 0.08$ & +1.02 & +1.0 \\
\hline $\mathrm{v}_{19}, \mathrm{cCc}$ bend & 430 & $1.20 \pm 0.12$ & +1.15 & +1.18 \\
\hline $\mathrm{v}_{20}, \mathrm{C}-\mathrm{I}$ stretch & 249 & $5.25 \pm 0.25$ & -5.25 & -5.25 \\
\hline
\end{tabular}

${ }^{a}$ Experimental frequeuncies.

${ }^{\mathrm{b}} \mathrm{A} b$ initio calculated results (See Calculations for more complete description of CIS and RPA computations). The calculated $\Delta$ have been scaled to the largest displacement (e.g., $|3.75|$ for axial and $|5.25|$ for equatorial). 
TABLE IV. Most probable internal coordinate displacements of axial and equatorial conformers of iodocyclopentane using the resonance Raman intensity analysis normal mode displacements with their signs determined from the $a b$ initio calculated gradient of the excited state.

\begin{tabular}{|c|c|c|}
\hline \multirow[b]{2}{*}{ Internal coordinate $^{a}$} & \multicolumn{2}{|c|}{ Range of displacement at $t=10 \mathrm{fs}$} \\
\hline & Axial conformer & Equatorial conformer \\
\hline $\mathrm{CHa}$ & $-0.0018 \AA$ & $+0.0014 \AA$ \\
\hline CI & $+0.0146 \AA$ & $+0.038 \AA$ \\
\hline $\mathrm{Cc}$ & $+0.0455 \AA$ & $+0.021 \AA$ \\
\hline $\mathrm{cHb}, \mathrm{cHd}$ & $+0.0007,+0.0030 \AA$ & $< \pm 0.001 \AA$ \\
\hline $\mathrm{cX}$ & $-0.0256 \AA$ & $-0.016 \AA$ \\
\hline XHe, XHf & $< \pm 0.001 \AA$ & $< \pm 0.001 \AA$ \\
\hline $\mathrm{XX}$ & $+0.0264 \AA$ & $+0.011 \AA$ \\
\hline $\mathrm{HaCI}$ & $-8.7^{\circ}$ & $-3.7^{\circ}$ \\
\hline $\mathrm{HaCc}$ & $+1.7^{\circ}$ & $+2.8^{\circ}$ \\
\hline $\mathrm{ICc}$ & $+1.5^{\circ}$ & $+0.02^{\circ}$ \\
\hline $\mathrm{cCc}$ & $+4.4^{\circ}$ & $-1.6^{\circ}$ \\
\hline $\mathrm{CcHb}$ & $+4.1^{\circ}$ & $-4.2^{\circ}$ \\
\hline $\mathrm{CcHd}$ & $+0.2^{\circ}$ & $-2.4^{\circ}$ \\
\hline $\mathrm{CcX}$ & $-7.0^{\circ}$ & $+0.4^{\circ}$ \\
\hline $\mathrm{HbcHd}$ & $+0.002^{\circ}$ & $+0.3^{\circ}$ \\
\hline $\mathrm{HbcX}$ & $-0.9^{\circ}$ & $+3.3^{\circ}$ \\
\hline HdcX & $+3.6^{\circ}$ & $+2.5^{\circ}$ \\
\hline $\mathrm{cXHe}$ & $+0.2^{\circ}$ & $-0.8^{\circ}$ \\
\hline cXHf & $+1.7^{\circ}$ & $-4.4^{\circ}$ \\
\hline $\mathrm{cXX}$ & $+2.9^{\circ}$ & $+0.1^{\circ}$ \\
\hline HeXHf & $-1.3^{\circ}$ & $0.0^{\circ}$ \\
\hline HeXX & $-0.4^{\circ}$ & $+1.1^{\circ}$ \\
\hline HfXX & $-3.0^{\circ}$ & $+4.0^{\circ}$ \\
\hline cCcx torsion & $+4.2^{\circ}$ & $+1.3^{\circ}$ \\
\hline $\mathrm{xcXx}$ torsion & $-0.1^{\circ}$ & $-1.4^{\circ}$ \\
\hline $\mathrm{xXXx}$ torsion & $-0.2^{\circ}$ & $+0.1^{\circ}$ \\
\hline
\end{tabular}

anote: $\mathrm{C}=$ the alpha carbon atom, $\mathrm{c}=$ the beta carbon atom, and $\mathrm{X}=$ the gamma carbon atom and the hydrogen atoms are labeled with subscripts $\mathrm{a}-\mathrm{f}$ (see Fig. 1 for corresponding diagrams of the axial and equatorial conformers of iodocyclopentane).

axial $\mathrm{v}_{12}$ and $\mathrm{v}_{13}$ modes $\left(1094 \mathrm{~cm}^{-1}\right.$ and $1034 \mathrm{~cm}^{-1}$, respectively) and the equatorial $\mathrm{v}_{11}, \mathrm{v}_{12}$, and $\mathrm{v}_{13}$ modes (1190,1110, and $1026 \mathrm{~cm}^{-1}$, respectively) is noticeably worse and it is not clear whether the calculations underestimate or the experiments overestimate the contributions of these modes to the short-time dynamics. There is good agreement in both sign and magnitude between the more simple CIS calculations and the higher level DT(RPA) density functional calculations and it appears reasonable to use the calculated signs of the normal mode displacements to choose the corresponding signs of the experimental values.

Table IV lists the internal coordinate displacements at 10 fs after photoexcitation for the most probable sign combinations of the normal coordinate displacements for the axial and equatorial conformers of iodocyclopentane. The shorttime dynamics presented in Table IV show distinctly different trends and can provide some insight into the major differences/similarities between the axial and equatorial conformation photodissociation reactions. Figure 1 (top) displays diagrams of axial and equatorial conformers of iodocyclopentane which can be used to help visualize the internal coordinate changes given in Table IV.

The internal coordinate changes at $t=10 \mathrm{fs}$ for the axial conformation are smaller for the $\mathrm{C}-\mathrm{I}$ stretch compared to the equatorial conformation $(+0.0146 \AA$ for axial and $+0.038 \AA$ for equatorial) while the axial changes are greater compared to the equatorial conformer for the Cc stretch $(+0.0455 \AA$ for axial and $+0.021 \AA$ for equatorial), the cX stretch $(-0.026 \AA$ for axial and $-0.016 \AA$ for equatorial $)$, the $\mathrm{XX}$ stretch $(+0.026 \AA$ for axial and $+0.011 \AA$ for equatorial $)$, the $\mathrm{HaCl}$ bend $\left(-8.7^{\circ}\right.$ or axial and $-3.7^{\circ}$ for equatorial $)$, the cCc bend $\left(+4.4^{\circ}\right.$ for axial and $-1.6^{\circ}$ for equatorial $)$, the $\mathrm{CcX}$ bend $\left(-7.0^{\circ}\right.$ for axial and $+0.4^{\circ}$ for equatorial $)$, the $\mathrm{cXX}$ bend $\left(+2.9^{\circ}\right.$ for axial and $+0.1^{\circ}$ for equatorial $)$, and the $\mathrm{xCcx}$ torsion $\left(+4.2^{\circ}\right.$ for axial and $+1.3^{\circ}$ for equatorial $)$. This suggests that the available energy of the $\mathrm{C}-\mathrm{I}$ bond dissociation is partitioned into noticeably different internal coordinate distributions for the axial and equatorial conformers in so far as the short-time dynamics correlate with the internal energy distributions of the cyclopentyl radical photoproduct. The Franck-Condon region $\mathrm{C}-\mathrm{I}$ bond length changes associated with the $A$-band photodissociation of iodoethane, 2-iodopropane, and 2-methyl-2-iodopropane show a reasonable correlation with the amount of internal energy and the widths of their internal energy distributions found for the radical photoproducts as determined by time-of-flight photofragment spectroscopy experiments. ${ }^{1,4,6,8,54,67,76,82}$ This suggests that the equatorial conformer of iodocyclopentane may produce cyclopentyl radicals with less internal excitation than the axial conformer in as much as the Franck-Condon region $\mathrm{C}-\mathrm{I}$ bond length changes correlate with the internal energy distributions of the cyclopentyl radical photofragments. This would be noticeably different than the case for iodocyclohexane which found that the cyclohexyl radicals formed from $A$-band photodissociation had more internal excitation for the equatorial conformer parent than the axial conformer parent $^{81}$ and may suggest that the energy partitioning of iodocyclopentane is significantly different than that of iodocyclohexane for their axial and equatorial conformations. However, time-of-flight photofragment spectroscopy and/or vibrational mode specific pump-probe experiments are needed for iodocyclopentane to determine if the energy partitioning for cyclopentyl radicals from axial and equatorial conformers is significantly different from that for cyclohexyl radicals formed from iodocyclohexane since our resonance Raman intensity analysis only probes the shorttime dynamics of the photodissociation reaction.

It is interesting that the CCI bend motion in Table IV at $10 \mathrm{fs}$ is relatively small and slightly positive for both the axial and equatorial conformations of iodocyclopentane and this is very similar to the equatorial iodocyclohexane $A$-band short-time dynamics $\left(0^{\circ}-0.35^{\circ}\right.$ at $\left.10 \mathrm{fs}\right) .^{82}$ This is in contrast to the noncyclic iodoalkanes (like iodoethane, 2-iodopropane, 1-iodopropane, 2-methyl-2-iodopropane, and others) which have fairly large negative CCI bend motion values in the $10-15$ fs range. ${ }^{67,72-79}$ Comparison of the results for the $A$-band short-time dynamics of iodocyclopentane and iodocyclohexane for the CCI bend motion with that found previously for many noncyclic iodoalkanes suggests that the cyclic backbone of iodocycloalkanes restricts the initial CCI bend motion compared to non-cyclic iodoalkane $A$-band photodissociation reactions.

The axial conformer changes in the carbon-carbon stretch internal coordinates $(\mathrm{Cc}, \mathrm{cX}$, and $\mathrm{XX})$ are noticeably 
larger than those for the equatorial conformer. This suggests that there may be more internal excitation of the carboncarbon stretch in the cyclopentyl radicals formed from the axial conformer than the equatorial conformer in so far as the initial dynamics correlate with the internal energy distributions of the cyclopentyl radicals. The fairly large negative change in the $\mathrm{HaCl}$ angle $\left(-8.7^{\circ}\right.$ for axial and $-3.7^{\circ}$ for equatorial) and accompanying positive change in the $\mathrm{HaCc}$ angle $\left(+1.7^{\circ}\right.$ for axial and $+2.8^{\circ}$ for equatorial $)$ is consistent with the $\mathrm{C}-\mathrm{I}$ bond cleavage kinematics of the $\alpha$-carbon atom being pushed into a semirigid radical. The $\mathrm{cCc}$ angle becomes larger for axial $\left(+4.4^{\circ}\right)$ but smaller for equatorial $\left(-1.6^{\circ}\right)$. This also appears to be consistent with the $\alpha$-carbon atom being pushed into a semirigid radical (the axial conformer pushes the $\alpha$-carbon atom toward the plane of the cXXc atoms while the equatorial conformer $\alpha$-carbon is moved further away from the cXXc plane). The larger internal coordinate changes for the carbon-carbon stretch and bending motions for the axial conformer relative to the equatorial conformer may account for the somewhat larger torsional motion about the $\mathrm{Cc}$ bond for the axial conformer. Several of the carbon-carbon-hydrogen bend motions display an interesting trend; the $\mathrm{CcHb}, \mathrm{CcHd}$, cXHe, cCHf, HeXX, and HfXX motions have different signs for the axial vs the corresponding motion in the equatorial conformation. It is not clear why this occurs. Since these motions are not as well determined as the lower frequency carbon/iodine ones (CC stretches, CCC bends, CCI bend, CI stretch, and torsions) from our resonance Raman intensity analysis, we will not speculate further on the HCC bending motions.

The most probable short-time dynamics for the axial and equatorial conformers are noticeably different from one another for many stretch, bend, and torsional motions which suggests that the available energy of the $\mathrm{C}-\mathrm{I}$ bond cleavage partitioned to the cyclopentyl radical photoproduct will have noticeably different distributions among the internal modes excited in so far as the initial dynamics determine the internal energy distributions of the cyclopentyl photofragment. The axial and equatorial conformation initial dynamics for the $\mathrm{C}-\mathrm{I}$ bond are noticeably different from one another and suggests that they may impart differing amounts of internal excitation to the cyclopentyl photoproduct. The axial conformer initial dynamics (at $10 \mathrm{fs}$ ) experiences larger changes in the $\mathrm{Cc}, \mathrm{cX}$, and $\mathrm{XX}$ stretches, the $\mathrm{cCc}, \mathrm{CcX}$, and $\mathrm{cXX}$ bending motions, and the $\mathrm{xCcx}$ torsional motion relative to the equatorial conformer. Comparison of the carboncarbon-iodine (CCI) bend initial photodissociation dynamics for both conformers of iodocyclopentane, the equatorial conformer of iodocyclohexane, ${ }^{82}$ and noncyclic iodoalkanes (such as iodoethane, 2-iodopropane, 2-methyl-2-iodoproane, and 1-iodopropane) $)^{67,72-79}$ shows that the cyclic iodocyclohexane and iodocyclopentane values are significantly smaller than the noncyclic iodoalkanes. This suggests that the cyclic backbone restricts the initial CCI bend motion compared to noncyclic iodoalkane $A$-band photodissociation reactions.

Further work is needed to better understand the axial and equatorial iodocyclopentane $A$-band photodissociation dynamics and energy partitioning. To obtain more accurate initial $A$-band dissociation dynamics, it might be beneficial to obtain resonance Raman spectra of isotopic derivatives of iodocyclopentane (such as deuterated or carbon 13 labeled derivatives) and/or attempt more sophisticated and computationally intensive ab initio calculations. The reader is referred to several recent review articles for more in depth discussions of the difficulties in choosing the signs of the normal mode displacements in resonance Raman intensity analysis investigations. ${ }^{98,99}$ Other experimental work to probe the energy partitioning for the A-band iodocyclopentane photodissociation products should prove very rewarding. Molecular beam experiments such as time-of-flight photofragment spectroscopy could determine the degree of internal excitation of the cyclopentyl radical photoproduct and vibrational mode-specific techniques such as multiphoton ionization (MPI), time-resolved infrared emission or absorption, and time-resolved Raman spectroscopy could elucidate the vibrational (and possibly the rotational as well) energy distributions for the cyclopentyl radical photoproduct. These types of experiments would enable a detailed investigation of how the initial $A$-band photodissociation dynamics of iodocyclopentane correlate with the internal excitation of the cyclopentyl radical photoproduct.

\section{ACKNOWLEDGMENTS}

This work was supported by grants from the Committee on Research and Conference Grants (CRCG), the Research Grants Council (RGC) of Hong Kong, the Hung Hing Ying Physical Sciences Research Fund and the Large Items of Equipment Allocation 1993-94 from the University of Hong Kong.

${ }^{1}$ S. J. Riley and K. R. Wilson, Faraday Discuss. Chem. Soc. 53, 132 (1972).

${ }^{2}$ R. K. Sparks, K. Shobatake, L. R. Carlson, and Y. T. Lee, J. Chem. Phys. 75, 3838 (1981).

${ }^{3}$ G. N. A. Van Veen, T. Baller, A. E. Devries, and N. J. A. Van Veen, Chem. Phys. 87, 405 (1984).

${ }^{4}$ M. D. Barry and P. A. Gorry, Mol. Phys. 52, 461 (1984).

${ }^{5}$ C. Paterson, F. G. Godwin, and P. A. Gorry, Mol. Phys. 60, 729 (1987).

${ }^{6}$ F. G. Godwin, C. Paterson, and P. A. Gorry, Mol. Phys. 61, 827 (1987).

${ }^{7}$ J. F. Black and I. Powis, Chem. Phys. 125, 375 (1988).

${ }^{8}$ Q. Zhu, J. R. Cao, Y. Wen, J. Zhang, Y. Huang, W. Fang, and X. Wu, Chem. Phys. Lett. 144, 486 (1988).

${ }^{9}$ K. Kinmura and S. Nagakura, Spectrochim. Acta 17, 166 (1961).

${ }^{10}$ A. Gedanken and M. D. Rowe, Chem. Phys. Lett. 34, 39 (1975).

${ }^{11}$ A. Gedanken, Chem. Phys. Lett. 137, 462 (1987).

${ }^{12}$ T. Donohue and J. Wiesenfeld, Chem. Phys. Lett. 33, 176 (1975).

${ }^{13}$ T. Donohue and J. Wiesenfeld, J. Chem. Phys. 63, 3130 (1975).

${ }^{14}$ W. H. Pence, S. L. Baughchum, and S. L. Leone, J. Phys. Chem. 85, 3844 (1981).

${ }^{15}$ P. Brewer, P. Das, G. Ondrey, and R. Bersohn, J. Chem. Phys. 79, 720 (1983).

${ }^{16}$ W. P. Hess, S. J. Kohler, H. K. Haugen, and S. R. Leone, J. Chem. Phys. 84, 2143 (1986).

${ }^{17}$ R. Ogorzalek-Loo, G. E. Hall, H.-P. Haerri, and P. L. Houston, J. Phys. Chem. 92, 5 (1987).

${ }^{18}$ F. G. Godwin, P. A. Gorry, P. M. Hughes, D. Raybone, T. M. Watkinson, and J. C. Whitehead, Chem. Phys. Lett. 135, 163 (1987).

${ }^{19}$ J. L. Knee, L. R. Khundar, and A. H. Zewail, J. Chem. Phys. 83, 1996 (1985).

${ }^{20}$ L. R. Khundar and A. H. Zewail, Chem. Phys. Lett. 142, 426 (1987).

${ }^{21}$ I. Powis and J. F. Black, J. Phys. Chem. 93, 2461 (1989).

${ }^{22}$ R. Ogorzalek-Loo, H.-P. Haerri, G. E. Hall, and P. L. Houston, J. Chem. Phys. 90, 4222 (1989).

${ }^{23}$ D. W. Chandler, M. H. M. Janssen, S. Stolte, R. N. Strickland, J. W. Thoman, Jr., and D. H. Parker, J. Phys. Chem. 94, 4839 (1990).

${ }^{24}$ G. E. Hall, T. J. Sears, and J. M. Frye, J. Chem. Phys. 90, 6234 (1989). 
${ }^{25}$ N. E. Triggs, M. Zahedi, J. W. Nibler, P. A. Debarber, and J. J. Valentini, J. Chem. Phys. 96, 2756 (1992).

${ }^{26}$ J. W. G. Mastenbroek, C. A. Taatjes, K. Nauta, M. H. M. Janssen, and S. Stolte, J. Phys. Chem. 99, 4360 (1995).

${ }^{27}$ D. G. Imre, J. L. Kinsey, A. Sinha, and J. Krenos, J. Phys. Chem. 88, 3956 (1984).

${ }^{28}$ M. O. Hale, G. E. Galica, S. G. Glogover, and J. L. Kinsey, J. Phys. Chem. 90, 4997 (1986).

${ }^{29}$ G. E. Galica, B. R. Johnson, J. L. Kinsey, and M. O. Hale, J. Phys. Chem. 95, 7994 (1991).

${ }^{30}$ K. Q. Lao, M. D. Person, P. Xayaroboun, and L. J. Butler, J. Chem. Phys. 92, 823 (1990)

${ }^{31}$ F. Markel and A. B. Myers, Chem. Phys. Lett. 167, 175 (1990).

${ }^{32}$ A. B. Myers and F. Markel, Chem. Phys. 149, 21 (1990).

${ }^{33}$ F. Markel and A. B. Myers, J. Chem. Phys. 98, 21 (1993).

${ }^{34}$ P. G. Wang and L. D. Zeigler, J. Phys. Chem. 97, 3139 (1993).

${ }^{35}$ B. R. Johnson and J. L. Kinsey, J. Phys. Chem. 100, 18937 (1996).

${ }^{36}$ F. Duschek, M. Schmitt, P. Vogt, A. Materny, and W. Kiefer, J. Raman Spectrosc. 28, 445 (1997).

${ }^{37}$ M. Shapiro and R. Bersohn, J. Chem. Phys. 73, 3810 (1980).

${ }^{38}$ S. K. Gray and M. S. Child, Mol. Phys. 51, 189 (1984).

${ }^{39}$ M. Shapiro, J. Phys. Chem. 90, 3644 (1986).

${ }^{40}$ M. Tadjeddine, J. P. Flament, and C. Teichteil, Chem. Phys. 118, 45 (1987).

${ }^{41}$ H. Guo and G. C. Schatz, J. Chem. Phys. 93, 393 (1990).

${ }^{42}$ Y. Amatatsu, K. Morokuma, and S. Yabushita, J. Chem. Phys. 94, 4858 (1991).

${ }^{43}$ H. Guo and G. C. Schatz, J. Phys. Chem. 95, 3091 (1991).

${ }^{44}$ H. Guo, J. Chem. Phys. 96, 2731 (1992).

${ }^{45}$ A. D. Hammerich, U. Manthe, R. Kosloff, H.-D. Meyer, and L. S. Cederbaum, J. Chem. Phys. 101, 5623 (1994).

${ }^{46}$ Y. Amatatsu, S. Yabushita, and K. Morokuma, J. Chem. Phys. 104, 9783 (1996).

${ }^{47}$ M. K. Dzvonik, S. Yang, and R. Bersohn, J. Chem. Phys. 61, 4408 (1974).

${ }^{48}$ M. Kawasaki, S. J. Lee, and R. Bersohn, J. Chem. Phys. 63, 809 (1975).

${ }^{49}$ P. M. Kroger, P. C. Demou, and S. J. Riley, J. Chem. Phys. 65, 1823 (1976).

${ }^{50}$ T. K. Minton, P. Felder, R. J. Brudzynski, and Y. T. Lee, J. Chem. Phys. 81, 1759 (1984).

${ }^{51}$ D. Krajnovitch, L. J. Butler, and Y. T. Lee, J. Chem. Phys. 81, 3031 (1984).

${ }^{52}$ G. N. A. Van Veen, T. Baller, A. E. DeVries, and M. Shapiro, Chem. Phys. 93, 277 (1985).

${ }^{53}$ Q.-X. Xu, K.-H. Jung, and R. B. Bernstein, J. Chem. Phys. 89, 2099 (1988).

${ }^{54}$ W. K. Kang, K. W. Jung, D. C. Kim, K.-H. Jung, and H. S. Im, Chem. Phys. 196, 363 (1995).

${ }^{55}$ W. K. Kang, K. W. Jung, D.-C. Kim, and K.-H. Jung, J. Chem. Phys. 104, 5815 (1995).

${ }^{56}$ R. J. Donovan, F. G. M. Hathorn, and D. Husain, Trans. Faraday Soc. 64, 3192 (1968)

${ }^{57}$ T. F. Hunter, S. Lunt, and K. S. Kristjansson, J. Chem. Soc., Faraday Trans. 2 79, 303 (1983).

${ }^{58}$ E. Gerck, J. Chem. Phys. 79, 311 (1983).

${ }^{59}$ S. Uma and P. K. Das, Can. J. Chem. 72, 865 (1994).

${ }^{60}$ D. H. Fairbrother, K. A. Briggman, E. Wietz, and P. C. Stair, J. Chem. Phys. 101, 3787 (1994)

${ }^{61}$ P. L. Ross and M. V. Johnston, J. Phys. Chem. 99, 4078 (1995).

${ }^{62}$ S. Uma and P. K. Das, Chem. Phys. Lett. 241, 335 (1995).

${ }^{63}$ S. Uma and P. K. Das, J. Chem. Phys. 104, 4470 (1996).

${ }^{64}$ J. Zhang and D. G. Imre, J. Chem. Phys. 89, 309 (1988).

${ }^{65}$ D. L. Phillips, B. A. Lawrence, and J. J. Valentini, J. Phys. Chem. 95, 7570 (1991).

${ }^{66}$ D. L. Phillips, B. A. Lawrence, and J. J. Valentini, J. Phys. Chem. 95, 9085 (1991).

${ }^{67}$ D. L. Phillips and A. B. Myers, J. Chem. Phys. 95, 226 (1991).

${ }^{68}$ D. L. Phillips, J. J. Valentini, and A. B. Myers, J. Phys. Chem. 96, 2039 (1992).

${ }^{69}$ W. M. Kwok and D. L. Phillips, Chem. Phys. Lett. 235, 260 (1995).

${ }^{70}$ D. L. Phillips and W. M. Kwok, Chem. Phys. Lett. 241, 267 (1995).

${ }^{71}$ S. Q. Man, W. M. Kwok, and D. L. Phillips, J. Phys. Chem. 99, 15705 (1995).
${ }^{72}$ W. M. Kwok and D. L. Phillips, J. Chem. Phys. 104, 2529 (1996).

${ }^{73}$ W. M. Kwok and D. L. Phillips, J. Chem. Phys. 104, 9816 (1996).

${ }^{74}$ S.-Q. Man, W. M. Kwok, A. E. Johnson, and D. L. Phillips, J. Chem. Phys. 105, 5842 (1996).

${ }^{75}$ W. M. Kwok, P. K. Ng, G. Z. He, and D. L. Phillips, Mol. Phys. 90, 127 (1997).

${ }^{76}$ D. L. Phillips and A. B. Myers, J. Raman Spectrosc. 28, 839 (1997).

${ }^{77}$ X. Zheng and D. L. Phillips, Chem. Phys. Lett. 286, 79 (1998).

${ }^{78}$ X. Zheng and D. L. Phillips, Chem. Phys. Lett. 292, 295 (1998).

${ }^{79}$ X. Zheng and D. L. Phillips, J. Chem. Phys. 108, 5772 (1998).

${ }^{80}$ X. Zheng and D. L. Phillips, Chem. Phys. Lett. 307, 350 (1999).

${ }^{81}$ J. E. Freitas, H. J. Hwang, A. B. Tricknor, and M. A. El-Sayed, Chem. Phys. Lett. 183, 165 (1991).

${ }^{82}$ X. Zheng and D. L. Phillips, Chem. Phys. Lett. 296, 173 (1998).

${ }^{83}$ I. O. C. Ekejiuba and H. E. Hallam, Spectrochim. Acta A 26, 59 (1970).

${ }^{84}$ I. O. C. Ekejiuba and H. E. Hallam, Spectrochim. Acta A 26, 67 (1970).

${ }^{85}$ P. Groner, M. J. Lee, and J. R. Durig, J. Chem. Phys. 94, 3315 (1991).

${ }^{86}$ V. V. Diky, G. J. Kabo, A. A. Kozyro, A. P. Krasulin, and V. M. Sevruk, J. Chem. Thermodyn. 25, 1169 (1993).

${ }^{87}$ J. R. Durig, H. M. Badawi, and D. T. Durig, J. Mol. Struct.: THEOCHEM 338, 267 (1995).

${ }^{88}$ J. Y. Shim, N. L. Allinger, and J. P. Bowen, J. Org. Chem. 61, 9245 (1996).

${ }^{89}$ T. Woldbaek, Acta Chem. Scand. A36, 641 (1982).

${ }^{90}$ D. E. Bugay, C. H. Bushweller, C. T. Danehey, Jr., S. Hoogasian, J. A. Blersch, and W. R. Leenstra, J. Phys. Chem. 93, 3908 (1989).

${ }^{91}$ H. Abramczyk, M. Barut, A. B. Altabef, and R. Escribano, J. Phys. Chem. 98, 424 (1994).

${ }^{92}$ A. B. Myers, B. Li, and X. Ci, J. Chem. Phys. 89, 1876 (1988).

${ }^{93}$ M. O. Trulson and R. A. Mathies, J. Chem. Phys. 84, 2068 (1986).

${ }^{94} \mathrm{~B}$. Li and A. B. Myers, J. Phys. Chem. 94, 4051 (1990).

${ }^{95}$ E. J. Heller, J. Chem. Phys. 62, 1544 (1975).

${ }^{96}$ S. Y. Lee and E. J. Heller, J. Chem. Phys. 71, 4777 (1979).

${ }^{97}$ E. J. Heller, R. L. Sundberg, and D. J. Tannor, J. Phys. Chem. 86, 1822 (1982).

${ }^{98}$ A. B. Myers and R. A. Mathies, in Biological Applications of Raman Spectroscopy, edited by T. G. Spiro (Wiley, New York, 1987), Vol. 2, p. 1.

${ }^{99}$ A. B. Myers, in Laser Techniques in Chemistry, edited by A. B. Myers and T. R. Rizzo (Wiley, New York, 1995), p. 325.

${ }^{100}$ E. B. Wilson, Jr., J. C. Decius, and P. C. Cross, Molecular Vibrations (Dover, New York, 1980).

${ }^{101}$ B. U. Curry, Ph.D. dissertation, University of California, Berkeley, 1983.

${ }^{102}$ See EPAPS Document No. E-JCPSA6-111-009948 for supporting information on normal coordinate and $a b$ initio calculations. This document may be retrieved via the EPAPS homepage (http://www.aip.org/pubservs/ epaps.html) or from ftp.aip.org in the directory /epaps/. See the EPAPS homepage for more information.

${ }^{103}$ Gaussian 98, Revision A. 7, M. J. Frisch, G. W. Trucks, H. B. Schlegel, G. E. Scuseria, M. A. Robb, J. R. Cheeseman, V. G. Zakrzewski, J. A. Montgomery, Jr., R. E. Stratmann, J. C. Burant, S. Dapprich, J. M. Millam, A. D. Daniels, K. N. Kudin, M. C. Strain, O. Farkas, J. Tomasi, V. Barone, M. Cossi, R. Cammi, B. Mennucci, C. Pomelli, C. Adamo, S. Clifford, J. Ochterski, G. A. Petersson, P. Y. Ayala, Q. Cui, K. Morokuma, D. K. Malick, A. D. Rabuck, K. Raghavachari, J. B. Foresman, J. Cioslowski, J. V. Ortiz, A. G. Baboul, B. B. Stefanov, G. Liu, A. Liashenko, P. Piskorz, I. Komaromi, R. Gomperts, R. L. Martin, D. J. Fox, T. Keith, M. A. Al-Laham, C. Y. Peng, A. Nanayakkara, C. Gonzalez, M. Challacombe, P. M. W. Gill, B. Johnson, W. Chen, M. W. Wong, J. L. Andres, C. Gonzalez, M. Head-Gordon, E. S. Replogle, and J. A. Pople, Gaussian, Inc., Pittsburgh, Pennsylvania, 1998.

${ }^{104}$ R. Bauernschmitt and R. Ahlrichs, Chem. Phys. Lett. 256, 454 (1996).

${ }^{105}$ X. G. Chen, S. A. Asher, R. Schweitzerstenner, N. G. Mirkin, and S. Krimm, J. Am. Chem. Soc. 117, 2884 (1995).

${ }^{106}$ X. G. Chen, R. Schweitzerstenner, S. A. Asher, N. G. Mirkin, and S. Krimm, J. Phys. Chem. 99, 3074 (1995).

${ }^{107}$ G. Stock, C. Woywod, W. Domcke, W. Swinney, and B. S. Hudson, J. Chem. Phys. 103, 6851 (1995).

${ }^{108}$ L. M. Markham and B. S. Hudson, J. Phys. Chem. 100, 2731 (1996).

${ }^{109}$ M. S. C. Foley, D. A. Braden, B. S. Hudson, and M. Z. Zgeirski, J. Phys. Chem. 101, 1455 (1997).

${ }^{110}$ M. Lilichenko, D. Tittelbach-Helmrich, J. W. Verhoeven, I. R. Gould, and A. B. Myers, J. Chem. Phys. 109, 10958 (1998). 